\title{
Critical Thinking in Research and Analysis for Business Development
}

\author{
James McKee., PhD \\ Retired - Wollongong University, Australia \\ Jim.mckee@ihug.com.au
}

\begin{abstract}
The aim of this paper is to highlight the need for more emphasis on the research and analysis required to obtain the right information needed for effective business development. The research examines the literature for examples of good practice for business research and analysis, which would lead to obtaining the most advantageous information for guiding the business. The result will show that insufficient attention is given in business studies to the analysis requirement to sift through vast amounts of available and interesting data for the critical useful information. More attention needs to be given to understand what information is most useful to the strategic development of the organisation. The limitation to this investigation is that the research is not empirical but normative in approach, but the practical result indicates that if more analysis subjects were included in business studies there will be better trained managers available. These managers would be better able to develop their organisation by having more meaningful information available to guide them in their strategic planning role.
\end{abstract}

Keywords: critical thinking, development, information, strategic planning, analysis

\section{The Importance of Information}

Today any organisation has to deal with a great deal of information and an even greater amount of data. In many instances the terms data and information are used interchangeably, and this can confuse the issue when trying to determine which information is particularly useful to the management of an organization. It is even harder to determine what is useful for planning the strategic development of the organisation.

We will examine the term information, the critical review of new information, and techniques on how to perform critical analysis to search out better value information. There is of course internal information about the company and information about its performance as well as external information about where the company sits within the market and in comparison with its competitors. Much of the internal information can be classed as originating from hard data from the internal operation of the company. There will be some soft data concerning the judgements about strengths and weaknesses and about what the value to the customer is and where the value to the organization can be found. However the external data must all be considered soft data unless it can be validated and confirmed in some way.

A definition of information from Alter (2002) is that: "information is data whose form and content are appropriate for a particular use". Another way to put this is that information can be used immediately without further manipulation by the recipient to take action or make a decision. This is a very useful definition because it also takes into account that what is useful information at one level of the organization may only be background data at a more senior level of the organization. Although this definition of information is fine within the ambit of information systems and the use of hard transaction data with its resolution into useful information; it does not go far enough when

The current issue and full text archive of this journal is available at www.jraspublications.org/index.php/JRAS/issue/archive Journal of Research in Administrative Sciences (JRAS) V IX(II), 6-9, ISSN: 2664-2433 we have to consider the soft data of opinions and subjective evaluations of competitors and customers that has to be considered for business development. As new data is collected, which may consist of some rumors, opinions, assumptions and estimates along with firmer data, it must be evaluated and integrated with any existing information to become the new knowledge base describing the potential of the company in the context of its environment.

Knowledge can be defined as information to which is added the experience and opinion of decision makers, another definition is that knowledge is information with added context to increase its value for strategic decision making (Chaffey and Wood, 2005). The new information should be measured and validated against existing related information, using the experience of the business development officer or analyst who should apply critical thinking or critical analysis to evaluate and connect the information as necessary.

The availability of an effective management information system (MIS) as part of a company's information system (IS), is essential to deal with the hard data from the internal operation of the organization in order to cope with today's business complexity. Lohman, Sol, \& de Vreede write that "[i]nformation [t]echnology can be used to derive such information ... However the contribution of the management information generated is disappointing. Many projects do not produce the results that organisations expect"... "[t]he 'information explosion' about which so much has been said and written, is to a great extent an explosion of misinformation and badly organised information" (2003).

The IS can generate an enormous volume of data so there needs to be careful attention given to determining what information will be required to develop the organization and to improve 
performance. This awareness can be used when developing the IS, to design it to incorporate the collection of as much useful data from operational activity as possible. This will better enable the management information system (MIS) to massage and reduce the data to meaningful, useful information for operational and tactical management.

Beyond the operational hard internal data from the IS, is the information about how effectively the elements of the organization work together, what their strength and weaknesses are, and where the operational value is? There is a need to identify the critical essential elements of information necessary for the optimum development of the organization, and the collection and storage of the essential information must be considered carefully in any business; a great deal of effort can be expended collecting less than useful data which is unhelpful when trying to run a business effectively.

The operational information system is unable to provide all the essential information for strategic planning, and there is a need for management to understand and develop an information management project to collect the additional soft information required from inside the company and external to the organization; gleaning what the effect might there be on the company when examining Porter's five forces. Soft data by its nature is subject to interpretation, even if it comprises published data; and the soft data may be interpreted differently when evaluating it for its information content by various members of the development team

Soft information must be evaluated for validity and accuracy, and the evaluation recorded with the information along with any assumptions and estimates. A useful mechanism to help validate soft information, is to try and ensure there is a triangulation of information from different sources and perspectives that can give confirmatory evidence to support each other. It can also be useful to ensure all concerned members of the team have a common understanding of what the information means, by having team discussions and agreeing a consensus description.

There are a number of authors (Alter, 2002, Brancheau and Wetherbie, 1986, Peffers et. al., 2003, and Robbins and di Cenzo, 2001) that warn of the danger of misinterpretation of verbal cues in documentation. The result of the differing perceptions could mean the staff leave a planning meeting with a variety of differing interpretations of the problem and therefore a range of ideas as to what the solution might be (McKee, 2018)

The Q Methodology by Mckeown and Thomas (1988) is one approach that can be used to avoid the misunderstanding of core concepts and the variety of meanings that can result from a description of a particular situation (2013)

Soft data and the resulting soft information is extremely difficult to obtain, and Porter in discussing the problem of gathering data about the competitive environment, suggests "the need for an organized mechanism - some sort of competitor intelligence system" to gather the soft data about the competition and declares that it is obtained more as a trickle of information over time, and most probably beyond the capability of any one person (Porter, 2004, p.72). Part of the system should include the training of the development officers tasked with gathering the information in interview and other analysis techniques.

\section{Critical Thinking}

Determining the key information that is required to describe the core of any development project should not be under estimated, and when planning strategically it is of even greater importance to identify the information that is needed to help formulate the development options for strategic planning. The key role of 'ready to use' information in any endeavor, is so important that there is an urgent need to understand how to distinguish critical information from the huge amount of irrelevant data. It requires the ability to question all new information, to determine its value and relevance and link it appropriately to the existing information. Critical thinking, the ability to ask effective questions and formulate original solutions, is not an optional skill in the $21^{\text {st }}$ century, critical thinking is self-directed, self-monitored, and self-corrective. It requires self-discipline to question new information and continuously analyze the results (Graham, 2017)

The vast amount of data that information systems are able to generate, much of which can be interesting, can misdirect and overwhelm the user, such that the real key information elements are overlooked. It is important to have a planned framework of required information, before beginning the search. It is also desirable to know how the essential information is to be catalogued and stored so that as new information is gathered it can be easily related to the accumulating story describing the business situation.

Instant answers, rather than thoughtful consideration or better questions, are the new measure of success in our country. But instant answers usually measure just two things: the ability to memorize, or, the access to technology. Let's face it. We all have the answers, usually right on our phones, but many of us, especially in the younger generation, are falling behind in our ability to ask the right questions or analyze the answers we get (Graham, 2017).

It requires self-discipline to question new information, particularly when it is produced by an information system or published in public documents, and to recognise the necessity to continuously question the new information and analyse and validate the results and conclusions as more information is gathered.

The concern expressed by Graham, that students and therefore graduates are not sufficiently aware of the urgent need to be critical in their acceptance of new information, is supported by the study by Puspita, Kaniawati and Suwarma which was aimed to know the critical thinking skills profile of senior high school students. "The results showed student's critical thinking skills are still low. Is almost every indicator of critical thinking skills only reaches less than $30 \%$. ... and the indicator for strategies and tactics was as low as 4\%" (Puspita, Kaniawati \& Suwarma, 2017). Wikipedia (2020) has several definitions of critical thinking, two are shown here:

"The process of actively and skillfully conceptualizing, applying, analyzing, synthesizing, and evaluating information to reach an answer or conclusion" (Dictionary.com).

According to Ennis, "Critical thinking is the intellectually disciplined process of actively and skillfully conceptualizing, applying, analyzing, synthesizing, and/or evaluating information gathered from, or generated by, observation, experience, reflection, reasoning, or communication, as a guide to belief and action." (Ennis, 2015)

Many universities have a student assessment help segment on their website advocating critical thinking or critical analysis as an aid to students, to help them understand and remember their studies. The recommended approach to learning and assessment can be seen to have a direct application to the research and analysis of business information, so several of these study suggestions have been paraphrased below where the concept of 'university studies' has been replaced with 'business investigations'

'Critical analysis' is a desirable skill in all aspects of [business investigations], but what actually is it? As Brown and Keely discuss, analysing critically is a process of deconstructing what you read, write and listen to in a rational and logical manner (2012). It requires you to move beyond describing and analyzing to evaluating, criticizing and postulating on what you process. Furthermore, you must be able to distinguish between what is evidence and what is an argument. This involves questioning assumptions, recognizing generalisations, and identifying bias in what you see, read and hear. Thinking critically helps you to uncover links across large and diverse bodies of knowledge enabling you to synthesize your own informed ideas.

Critical analysis requires the following:

- Provide informed reasoning backed by evidence and ideas from trustworthy [source].

- Identify context, background and/or bias that may lead to distortion within what you read and hear.

- Identify and question unfounded assumptions.

- Explain the significance and consequences of particular data, arguments and conclusions made by others (Drew \& Bingham 2001, pp. 281 - 282). Reprinted from - UOW.html, 2020, in advice to students for learning and assessments.

Marita and Mathee (2020) present a case for the use of critical thinking as a means to assess the quality and credibility of online content. And suggest "A useful definition for critical thinking is therefore the one suggested by Tiruneh and his co-authors: critical thinking is the ability to analyse and evaluate arguments according to their soundness and credibility, respond to arguments and reach conclusions through deduction from given information (Tiruneh, Verburgh and Elen, 2014). 


\section{Analyzing Information Critically}

The New Zealand Open Polytechnic add to the concept of thinking critically or critical analysis with some important analysis techniques:

[W] hen you think analytically you examine, or think about, the different parts or details of something so that you can understand or explain it. It requires you to think about some (or all) of the following:

- cause and effect, the sequence of events and/or steps within a process

- similarities, differences and/or trends

- associations and relationships between things

- complex systems and how they work

- ways to solve complex problems

- When you are analyzing information, ask yourself questions. For example:

- Where does the information come from? Where can I find out more?

- When did it happen? When was the research done?

- Why did this happen? Why do/did people feel the way they do?

- What happened before this, and after it? What does it really mean? What do others think about it?

- How do the bits fit together and relate to one another (Tuwhera, 2020).

\section{Business Analysis}

The above examples of critical thinking and critical analysis are aimed at students to help them study by questioning what they are reading and by challenging what others are saying; however evidence indicates that many students still do not acquire these skills and a report by 'Payscale' indicates that "Sixty percent of hiring managers feel that recent college graduates aren't adequately adept at critical thinking and problem solving" (Payscale, 2016). Rider University go further than just having a guide on their web site available to students, and pursue the problem of the lack of critical thinking skills in graduates by suggest that "Professionals looking to advance their critical thinking skills can benefit from pursuing an online Master of Arts in Business Communication degree" at Rider, where they try to answer the question of 'why is critical thinking important in business?'

Business leaders take major actions every day, from hiring and firing to reviewing financial earnings reports, participating in board meetings and handling public relations crises. These are the precise areas in which critical thinking comes into play, as business leaders use this skill to make tough decisions.

When applying critical thinking in business, a leader must use logic to identify, understand, analyse and solve problems. This requires patience and practice. The successful application of critical thinking often results in more efficient work processes and are important to improve communication strategies, support smooth operations and streamline product development. (Rider University, 2020). The obvious addition to these three examples of business functions that can be improved by critical thinking and logical analysis, is the research and investigation required for strategic business development.

To acquire the information that is needed to design a new application system, the designated situation must be researched and the results analyzed to determine the essential requirements. When developing the IT system, the analysis is all about identifying the processes, the decision points and the resulting actions; what data that comes into the situation, any required transformation and the data that is output. The facts already exist, but their sequence and dependencies need to be determined, and when commencing the business investigations for competitive advantage and the search needs to obviously extend more thoroughly into what makes the business work effectively and to look outward into the surrounding business environment for threats and opportunities.

To determine an effective development strategy, a company must first be reviewed for its business competencies, the process analysis that has been done for an IT system will be useful, but the research and analysis team of business development officers must go much deeper into the internal operations to determine the value chain (or value architecture) and search out any dependencies that link to other business elements and draw inferences and conclusions for changes to create advantage. The development team need to research the market and other circumstances surrounding the operation of the company to examine carefully what effect Porter's five forces may have on the future of the company. They will then need to surmise what threat these factors might be on the strengths and weaknesses of the company's internal resources, this view of assessing competitive development is known as the 'resource based view', "the resource based view (RBV) of the firm, and the need to understand the strategically relevant resources a firm had available to enhance their competitive standing" (Sorensen, 2012, p. 215) and this information should also be recorded along with any assumptions and motivations. The information analysis needs to be discussed with management, and change options selected for evaluation before the final choices made of what changes will be needed to create development opportunities.

The research and analysis of the events and circumstances outside the company are much more difficult to investigate than the resources inside the company, Porter gives a very useful description of the functions of a competitor intelligence system which has the two features of gathering field data and collecting published data, and sources from both features need to be treated with caution.

Field data, includes reports from the company's staff in sales, engineering and distribution channels, also professional meetings and trade associations etc. When considering information from these sources it is advisable to bear in mind Alter's warning about misconceptions people make when passing on information they have heard. People may have a tendency to use the most recent data and ignore contrary older data but also may make assumptions from an inappropriate associative cues in the dialogue (Alter, 2002), this may be especially be true when asked to pass on their impressions from customers, sellers and the marketplace generally.

The list of possible sources for published data e.g. articles, newspapers in particular market locations, government documents, analyst's reports etc. should be investigated for useful information but for all these sources of soft data the warnings from Alter and Chaffey and Wood and others must be borne in mind and the above list of question and warnings on critical thinking and critical analysis is very pertinent. Chaffey \& Wood (2005) suggest that it is necessary to also ask what evidence supports the information, how accurate the information is, how reliable is the source? Drew \& Bingham in their paper on critical analysis suggest it is necessary to:

- Identify context, background and/or bias that may lead to distortion within what you read and hear.

- Identify and question unfounded assumptions. (Drew \& Bingham, 2001, pp. 281 - 282).

The suggestion is that to gather this kind of information, it is essential to be properly trained in analysis and interview techniques and it is relevant that Rider University have included the subject as part of their Master's degree. Most Universities have subjects and entire courses on information systems analysis but it is rare to see similar analysis subjects in a business degree. The complexity of gathering business information, assessing it for accuracy and timeliness and collating it with existing information and filing the information with its audit report on the accuracy evaluation; certainly merits substantial training on the techniques required to do the job properly.

The development officers will need to make assumptions and to suggest conclusions or make predictions and it will be useful to iterate the research and analysis as the story develops; starting with an outline of the possible scenario then developing a broad brush of major elements and gradually filling in the detail as the story becomes clearer.

They need to look for cause and effect relations and the degree of dependency, they need to determine what supporting events or business elements are required to make something happen. The business information element may be as ambivalent as the relative profile of a competitive brand name or the position of a store in a high traffic area. The information element itself along with assumptions and relationships and how it may be related to 
increasing the value for the customer and to the company needs to be noted.

As the story develops of the company and its interaction with the competition, the analysts should be looking for patterns of relationship and influence and will have to make predictions of consequence by extrapolating the possibilities. They need to establish what connections exist between the various elements of doing business looking at the company's resources, such as: the customers, the products, the suppliers, the supplier pool, the skills supply, the demographics, the marketplace, the competition and anything else related to doing business.

A methodology of comprehensive analysis is required to deal with searching out the range of complex issues and factors comprising the complete business enterprise and its environment, and this will be covered in a later paper.

Of course all of this information is dynamic and changing, so it is important for this information to be well organized and well structured, so that any required aspect can be readily found; but also, so that as things change, it is relatively easy to extract the relevant component and update it. Having a predetermined framework (or architecture) for new information to fit into, is of enormous benefit when trying to manage the collection and storage over time for so much information.

An information architecture designed for the task of describing the organization and its position relative to the Porter's five forces for competitive advantage is an important facility; providing a guiding role and important communication tool to the development officers, and an important structured description for discussion by the planners (Mckee, 2017).

It is only with a complete description of the organisation defined by the use of a business architecture that managers can see the whole structure of the organisation and the essential intersections, constraints and supporting mechanisms that they can properly evaluate potential risks and opportunities (McKee, 2017, p.92). The complexity of the research and analysis task demands that it be treated as a development project so that the approach to collecting and storing the information is correctly planned, and the development officers need training to accomplish this difficult task. It is important to acknowledge the value of having an information policy and an information management system in place so that the information is collected, verified, collated and stored appropriately for retrieval and use.

\section{References}

i. Alter, S. (2002). Information Systems: The Foundations of EBusiness. New Jersey, Prentice Hall - Pearson Education International.

ii. Chaffey, D., \& Wood, S. (2005). Business Information Management: Improving Performance using Information Systems, Prentice Hall - Financial Times.

iii. Ennis, R., H. (2015). 'Critical Thinking', The Palgrave Handbook of Critical Thinking in Higher Education, Palgrave Macmillan.

iv. Graham, S. (2015). "Thinking Matters: Critical Thinking Is Crucial for Success." Retrieved 28/09/2020, 2020.

v. Lohman, F. A. B., Sol, H. G., \& de Vreede, G. (2003). "The Illuson of Effective Management Information." International Journal of Technology, Policy and Management 3(3/4).

vi. McKee, J. (2018). Business Architecture for Risk Assessment and Strategic Planning: Emerging Research and Opportunities. Hershey PA, IGI Global.]PayScale, (2017) "These 5 Soft Skills Will Get You Hired" retrieved from https://www.payscale.com/career-news/2017/10/these-5-softskills-will-get-you-hired

vii. Porter, M. E. (1985). Competitive Advantage: Creating and Sustaining Superior Performance. New York, The Free Press. A division of Maximillan Inc.

viii. Puspita, I., Kaniawati, I., and Suwarma, I. R., (2017). "Analysis of Critical Thinking Skills on The Topic of Static Fluid." Journal of Physics Conference Series 895(1):012100.

ix. Rider University. (2020). "Why Is Critical Thinking Important in Business?" Retrieved 28/09/2020, 2020, from https://online.rider.edu.

x. Tiruneh, D. T., Verburgh, A., and Elen, J. (2014). "Effectiveness of Critical Thinking Instruction in Higher Education: A Systematic Review of Intervention Studies." Higher Education Studies 4(1) xi. Tuwhera, K. (2020). "Thinking critically and evaluating information." Retrieved 29/09/2020, 2020, from https://www.openpolytechnic.ac.nz/study-with-us/studentstories.

xii. University of Wollongong. (2020). "Critical analysis." Retrieved 4/10/2020, from https://www.uow.edu.au/student/learning-coop/assessments/critical-analysis/.

xiii. Wikepedia. (2020). "Critical Thinking." From https://en.wikipedia.org/wiki/Critical_thinking.

xiv. Zyl, A., Turpin, M., and Mathee, M. (2020). How Can Critical Thinking Be Used to Assess the Credibility of Online Information? Conference on e-Business, e-Services and eSociety Springer, Cham. 